\title{
Angiographic estimation of atherosclerotic disease burden in a coronary artery fed by collaterals: a potential pitfall in decision for revascularization
}

\author{
This article was published in the following Dove Press journal: \\ Vascular Health and Risk Management \\ 21 March 201। \\ Number of times this article has been viewed
}

\section{Grigorios Tsigkas \\ Panagiota Mylona \\ Periklis Davlouros \\ Dimitrios Alexopoulos \\ Cardiology Department, University Hospital of Patras, Patras, Greece}

Correspondence: Grigorios Tsigkas Patras University Hospital, Rion Patras 26500, Greece

Tel +3026 I099 928I

Fax +30 2610992941

Email gregtsig@hotmail.com

\begin{abstract}
Despite the remarkable advances in revascularization strategies made during the last decade, a significant proportion of patients are excluded from either percutaneous coronary intervention or coronary artery bypass grafting because of unsuitable coronary anatomy. Diffuse severe coronary artery disease, small vessel caliber, chronic total occlusions, or extremely calcified vessels are frequent reasons for deferring revascularization with either percutaneous coronary intervention or coronary artery bypass grafting. We present a case concerning a middle-aged asymptomatic patient who was treated successfully with percutaneous coronary intervention due to a chronic total occlusion lesion of the left anterior descending artery. Coronary angiography is an inadequate method for the estimation of the burden of atherosclerotic disease in an artery fed by collaterals. Assessment of any residual antegrade flow, and ipsilateral and contralateral collateral filling of the segments distal to the occlusion with invasive or noninvasive techniques, could affect the appropriate decision-making by physicians.
\end{abstract}

Keywords: collaterals, percutaneous coronary intervention, coronary artery bypass grafting, ischemia, revascularization, chronic total occlusion

\section{Introduction}

Diffuse severe coronary artery disease, small vessel caliber, chronic total occlusions, or extremely calcified vessels are frequent reasons for deferring revascularization with either percutaneous coronary intervention or coronary artery bypass grafting. ${ }^{1}$ Presumably, estimation of such angiographic characteristics in a culprit vessel with a proximal total occlusion is feasible only through a well developed collateral network. There is general agreement that optimal medical treatment is the cornerstone of coronary artery disease management. Meanwhile, there is no doubt that timely revascularization offers a benefit in controlling patients with severe symptoms and may also offer a survival benefit in patients with diffuse disease and diabetes. ${ }^{2}$ Known techniques and innovations are crucial if old, calcified, and long chronic total occlusions are to be recanalized, proceeding with percutaneous coronary intervention. On the other hand, coronary artery bypass grafting is the basic alternative for treatment of diffusely diseased vessels not amendable to percutaneous coronary intervention. We present a case concerning a middle-aged asymptomatic patient who was treated successfully with percutaneous coronary intervention due to a chronic total occlusion lesion of the left anterior descending artery, despite initial misleading angiographic images. 


\section{Case report}

An asymptomatic 47-year-old male patient with a strong family history of coronary artery disease was admitted for coronary angiography due to a positive exercise stress test followed by a thallium scan which showed extensive ischemia of the anterior left ventricular wall. An echocardiogram revealed mild apical left ventricular hypokinesia with preserved global left ventricular ejection fraction. Coronary angiography showed a chronic total occlusion of the proximal part of the left anterior descending artery, along with a $40 \%$ stenosis of the left circumflex artery, and a normal right coronary artery. Beyond the proximal left anterior descending artery occlusion, the vessel was opacified through ipsilateral (Figure 1A) and mostly contralateral collaterals (Rentrop Grade 2), ${ }^{3}$ and appeared to have diffuse atheroma with at least three severe angiographic stenoses extending to its distal part (Figure 1B). This angiographic anatomy suggested that if percutaneous coronary intervention was selected as the initial therapeutic strategy, following a presumably successful treatment of the chronic total occlusion, multiple stents would be needed to restore full vessel patency. On the other hand, revascularization with coronary artery bypass grafting would require an extensive endarterectomy distal to the implantation of an arterial graft. Therefore, an attempt at percutaneous coronary intervention with a plan for referral for coronary artery bypass grafting if the former was unsuccessful was decided. Surprisingly, following successful stenting of the proximal left anterior descending artery occlusion with a paclitaxel-eluting stent, it became evident that, distal to the latter, the vessel had diffuse atherosclerosis, but without any other significant angiographic stenosis as the initial angiography had suggested (Figure 2). The patient had an

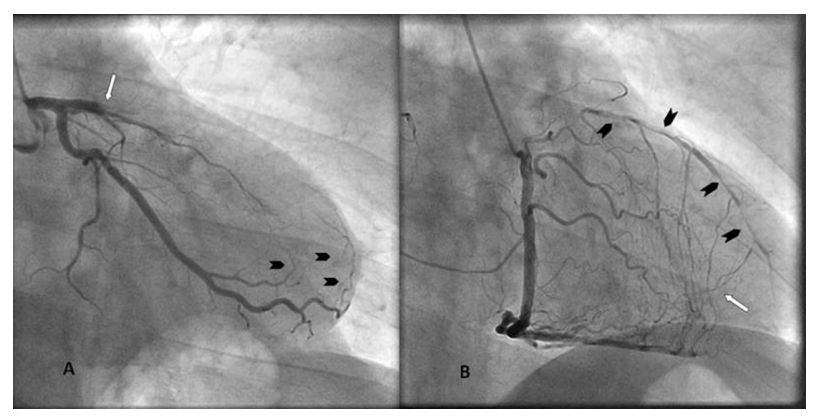

Figure I A) Right anterior oblique caudal view of left anterior descending artery. Total proximal occlusion of left anterior descending artery (white arrow). Arrowheads indicate mild ipsilateral collaterals from the obtuse marginal to the left anterior descending artery. B) Straight right anterior oblique view of right coronary artery. Contralateral collaterals from the right coronary artery are feeding the distal part of the left anterior descending artery (white arrow), giving the impression of a narrow and multi-atheromatous vessel. Arrowheads show severe and diffuse atheroma in the left anterior descending artery. (Image courtesy of the Catheterization Laboratory at Patras University Hospital).

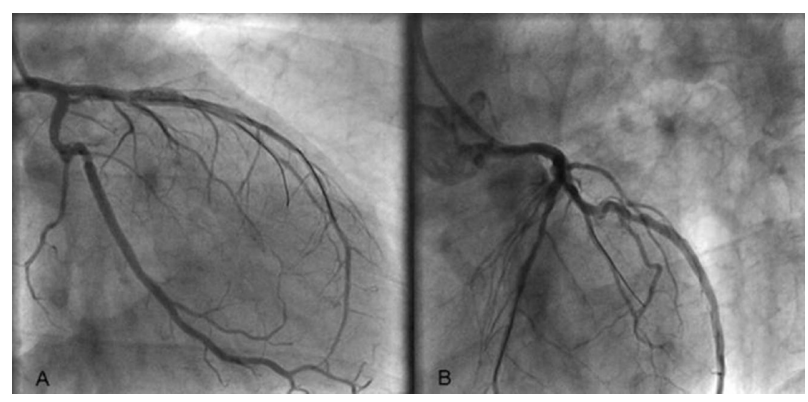

Figure 2 Right anterior oblique caudal (Panel A) and left anterior oblique; cranial (Panel B) projection of left anterior descending artery. After stent apposition, left anterior descending artery appears as a diffusely atheromatous vessel without critical stenosis. One more guide wire was used in order to protect the diagonal branch. (Image courtesy of the Catheterization Laboratory at Patras University Hospital).

uneventful recovery and was discharged after three days. Follow-up at six months with an exercise treadmill test showed no electrocardiographic signs of ischemia and an excellent exercise tolerance.

\section{Discussion}

More than $30 \%$ of patients with significant coronary artery disease present with chronic total occlusions. ${ }^{4}$ In such patients, the existence of a collateral circulation supplying the myocardium distal to a severe stenosis or total occlusion may improve ventricular function, minimize the infarcted area, reduce the incidence of left ventricular aneurysm formation, and lead to improved survival compared with patients lacking a well developed collateral network. ${ }^{5}$ Additionally, the existence of the latter allows angiographic assessment of the involved vessel beyond the level of the chronic total occlusion. The extent of collateral flow is not always adequately estimated by coronary angiography, because there is a capacity for further dilatation in response to neurohumoral mediators. ${ }^{6}$ There are controversial opinions and results in the literature concerning the proper treatment of severe but asymptomatic coronary artery disease. ${ }^{7}$ Conversely, recanalization of chronic total occlusions, especially when the left anterior descending artery is involved, with percutaneous coronary intervention can reduce mortality and the need for bypass surgery, ${ }^{8}$ and even improve symptoms and prognosis. ${ }^{9}$ If coronary artery bypass grafting is selected as the initial therapeutic strategy, optimal visualization of the target vessel in its entire length through feeding collaterals is mandatory for deciding the feasibility of the former, but the surgeon should also construct a plan for the site of graft implantation, and the potential need for downstream endarterectomy. Obviously, close collaboration between cardiologists and surgeons is needed to balance the feasibility and risks of surgery versus percutaneous coronary 
intervention for cases in which the angiographic anatomy of the target vessel constitutes the critical point upon which the joint therapeutic decision is based.

Coronary blood flow depends on the balance between coronary artery perfusion pressure and flow resistance in the coronary tree. The main limitation of coronary angiography is that collateral flow detection provides only an estimate of the absolute collateral flow. A momentarily altered balance between vasodilatation and vasoconstriction in the infarct-related artery could affect and could be affected by the flow through collaterals, potentially leading to a false angiographic estimation of lumen characteristics. Antegrade flow and flow through collaterals are constantly under an active balance. There are at least two possible explanations for the observed discrepancy between the angiographic assessment of coronary collateral vessels and rest or stress myocardial perfusion. First, coronary angiography depicts only those epicardial collateral channels with a lumen diameter $>100 \mu \mathrm{m},{ }^{10}$ but the most numerous and probably most important subendocardial and intramural intercoronary channels, ${ }^{11}$ about $20 \mu \mathrm{m}$ in diameter, ${ }^{12}$ are not visualized. Second, the development and visualization of collateral vessels depend, at least in part, on the transanastomotic pressure, and could have an additional effect on angiographic visualization of the main vessel, which remains frequently a major channel supporting myocardium perfusion distally to the blockage of the artery. ${ }^{13}$

Because angiography in this situation may be proved unreliable, noninvasive imaging techniques that may assist better image guidance during chronic total occlusion revascularization, such as computed tomography angiography and invasive high fidelity intracoronary imaging with optical coherence tomography, might be useful for studying the lumen of the target vessel and guiding therapy. ${ }^{14}$

\section{Conclusion}

In conclusion, the degree of distal vessel filling, not only via collateral circulation, and the resulting angiographic estimation of lumen characteristics, may affect medical and surgical decisions potentially impacting on the outcome for the patient, especially when the left anterior descending artery is involved. Hence, our case exemplifies that even reasonable opacification of the target vessel through collaterals, may be misleading for the construction of a surgical plan, and most importantly, for final decision-making.

\section{Disclosure}

The authors report no conflicts of interest in this work.

\section{References}

1. Ivanhoe RJ, Weintraub WS, Douglas JS Jr, et al. Percutaneous transluminal coronary angioplasty of chronic total occlusions. Primary success, restenosis, and long-term clinical follow-up. Circulation. 1992;85: 106-115.

2. Magro M, Garg S, Serruys PW. Revascularization treatment of stable coronary artery disease. Expert Opin Pharmacother. 2011;12: 195-212.

3. Rentrop KP, Cohen M, Blanke H, Phillips RA. Changes in collateral channel filling immediately after controlled coronary artery occlusion by an angioplasty balloon in human subjects. J Am Coll Cardiol. 1985; 5:587-592.

4. Delacretaz E, Meier B. Therapeutic strategy with total coronary artery occlusions. Am J Cardiol. 1997;79:185-187.

5. Habib GB, Heibig J, Forman SA, et al. Influence of coronary collateral vessels on myocardial infarct size in humans. Results of phase I thrombolysis in myocardial infarction (TIMI) trial. The TIMI Investigators. Circulation. 1991;83:739-746.

6. Komaru T, Kanatsuka H, Shirato K. Coronary microcirculation: Physiology and pharmacology. Pharmacol Ther. 2000;86:217-261.

7. Gershlick T, Thomas M. PCI or CABG: Which patients and at what cost? Heart. 2007;93:1188-1190.

8. Joyal D, Afilalo J, Rinfret S. Effectiveness of recanalization of chronic total occlusions: A systematic review and meta-analysis. Am Heart J. 2010;160:179-187.

9. Leung WH, Lau CP. Effects of severity of the residual stenosis of the infarct-related coronary artery on left ventricular dilation and function after acute myocardial infarction. J Am Coll Cardiol. 1992;20: 307-313.

10. Gensini GG, Bruto da Costa BC. The coronary collateral circulation in living man. Am J Cardiol. 1969;24:393-400.

11. Gregg DE, Patterson RE. Functional importance of the coronary collaterals. N Engl J Med. 1980;303:1404-1406.

12. Di Carli M, Sherman T, Khanna S, et al. Myocardial viability in asynergic regions subtended by occluded coronary arteries: Relation to the status of collateral flow in patients with chronic coronary artery disease. J Am Coll Cardiol. 1994;23:860-868.

13. Traupe T, Gloekler S, de Marchi S, Werner G, Seiler C. Assessment of the human coronary collateral circulation. Circulation. 2010;122: 1210-1220.

14. Courtney B, Munce N, Anderson K, et al. Innovations in imaging for chronic total occlusions: A glimpse into the future of angiography's blind-spot. Eur Heart J. 2008;29:583-593.
Vascular Health and Risk Management

\section{Publish your work in this journal}

Vascular Health and Risk Management is an international, peerreviewed journal of therapeutics and risk management, focusing on concise rapid reporting of clinical studies on the processes involved in the maintenance of vascular health; the monitoring, prevention and treatment of vascular disease and its sequelae; and the involvement of

\section{Dovepress}

metabolic disorders, particularly diabetes. This journal is indexed on PubMed Central and MedLine. The manuscript management system is completely online and includes a very quick and fair peer-review system, which is all easy to use. Visit http://www.dovepress.com/ testimonials.php to read real quotes from published authors. 